\title{
Determination of common urine substances as an assay for improving prostate carcinoma diagnostics
}

\author{
ZBYNEK HEGER $^{1}$, NATALIA CERNEI ${ }^{1,2}$, JAROMIR GUMULEC $^{2,3}$, MICHAL MASARIK $^{2,3}$, \\ TOMAS ECKSCHLAGER ${ }^{4}$, ROMAN HRABEC ${ }^{5}$, ONDREJ ZITKA ${ }^{1,2}$, VOJTECH ADAM $^{1,2}$ and RENE KIZEK ${ }^{1,2}$ \\ ${ }^{1}$ Department of Chemistry and Biochemistry, Faculty of Agronomy, Mendel University in Brno, CZ-613 00 Brno; \\ ${ }^{2}$ Central European Institute of Technology, Brno University of Technology, CZ-616 00 Brno; ${ }^{3}$ Department of Pathological \\ Physiology, Faculty of Medicine, Masaryk University, CZ-625 00 Brno; ${ }^{4}$ Department of Paediatric Haematology \\ and Oncology, 2nd Faculty of Medicine, Charles University, and University Hospital Motol, CZ-15006 Prague 5; \\ ${ }^{5}$ Department of Urology, St. Anne's University Hospital, CZ-656 91 Brno, Czech Republic
}

Received October 7, 2013; Accepted December 2, 2013

DOI: $10.3892 / o r .2014 .3054$

\begin{abstract}
Recently, interest in the identification of non-invasive markers for prostate carcinoma detectable in the urine of patients has increased. In this study, we monitored the abundance of potential non-invasive markers of prostate carcinoma such as amino acid sarcosine, involved in the metabolism of amino acids and methylation processes, ongoing during the progression of prostate carcinoma. In addition, other potential prostate tumor markers were studied. The most significant markers, prostate-specific antigen (PSA) and free PSA (fPSA), already used in clinical diagnosis, were analyzed using an immunoenzymometric assay. Whole amino acid profiles were also determined to evaluate the status of amino acids in patient urine samples and to elucidate the possibility of their utilization for prostate carcinoma diagnosis. To obtain the maximum amount of information, the biochemical parameters were determined using various spectrophotometric methods. All results were subjected to statistical processing for revealing different correlations between the studied parameters. We observed alterations in most of the analyzed substances. Based on the results obtained, we concluded that the specificity of prostate carcinoma diagnosis could be improved by determination of common urine metabolites, since we compiled a set of tests, including the analysis of sarcosine, proline, PSA and uric acid in the urine. These metabolites were not observed in the urine obtained from healthy subjects, while their levels were elevated in all patients suffering from prostate carcinoma.
\end{abstract}

Correspondence to: Professor Rene Kizek, Department of Chemistry and Biochemistry, Mendel University in Brno, Zemedelska 1, CZ-613 00 Brno, Czech Republic

E-mail:kizek@sci.muni.cz

Key words: sarcosine, proline, PSA, ion-exchange liquid chromatography, immunoenzymometric assay, spectrophotometry

\section{Introduction}

In 2013, cancer of the prostate $(\mathrm{CaP})$ was determine to be the most common type of tumor in males in the United States $(1,2)$ and worldwide (3). Early diagnostis of $\mathrm{CaP}$ is important due to the increase in treatment success leading to elimination of metastatic expansion. Currently, there is no complex test available for CaP diagnosis and evaluation of prostate cancer stage (4). The testing process usually used for the diagnosis of $\mathrm{CaP}$ includes digital rectal examination, determination of prostate-specific antigen (PSA) (5), transrectal sonography with biopsy of the prostate (6), magnetic resonance imaging (7) and positron emission tomography (8). PSA, first described in 1977 (9), is the most widely used biomarker of $\mathrm{CaP}$ to date. It is commonly used to estimate the stage of disease and disease progression. Despite the fact that the sensitivity (49-91\%) and the specificity $(68-80 \%)$ of PSA are high, the prognosis estimate is unreliable, in early stages in particular (10). In this context, new biomarkers of $\mathrm{CaP}$ carcinoma are increasingly studied with the prospect to serve as a useful tool for early diagnosis without clinical examinations and/or invasive interventions $(11,12)$. Novel potential biomarkers with the possibility to be determined in urine include $\alpha$-methylacyl-CoA-racemase (AMACR) (13), PCA3 (prostatic antigen 3) $(14,15)$ and Annexin A3 $(13,16)$. Other reported potential biomarkers detectable in serum include kallikrein 2, fibronectin 1, urokinase-type plasminogen activator/urokinase-type plasminogen activator receptor, pigment epithelium-derived factor (PEDF), interleukin-6 and interleukin- 6 receptor $(17,18)$. Nevertheless, the use of these markers in clinical practice and their role in the active surveillance scenario require further investigation. The amino acid sarcosine is currently the most studied biomarker showing the capability to serve as a diagnostic substance for the early stages of prostate carcinoma. Interest in this molecule was increased in 2009 when Sreekumar and colleagues (19) published their study regarding metabolomic profiles of urine obtained from $\mathrm{CaP}$ patients. Even though the linkage of sarcosine with prostate carcinoma development was reported $(20,21)$ as well as its 
potential in the diagnosis of early-stage tumors $(4,22)$, its use as a marker is still under discussion (23). Hence, it is necessary to study the functions of sarcosine and other amino acids, acting as the intermediate products of metabolism influenced by tumor growth. Therefore, the aim of the present study was to determine the amino acid profile of urine samples obtained from patients suffering from $\mathrm{CaP}$ and to compare them with control subjects. Biochemical analyses of samples were also carried out, and the sarcosine content was determined. Further statistical analysis was performed to reveal correlation between the parameters obtained.

\section{Materials and methods}

Biological samples. Urine samples from patients suffering from cancer of the prostate $(n=32)$, obtained from the Department of Urology, St. Anne's University Hospital, Brno were used. The average age of the patients was 68.45 years. All cases were diagnosed with different types of acinar adenocarcinoma. Detailed information concerning the patients is documented in Table I. For a control measurement, urine samples from volunteers $(n=32)$ with an average age of 24.69 years were used. Enrollment of patients into the clinical study was approved by the Ethics Committee of the Faculty of Medicine, Masaryk University, Brno, Czech Republic.

Chemicals and pH measurement. All chemicals were obtained from Sigma-Aldrich (St. Louis, MO, USA) at ACS-specified purity unless noted otherwise. As a buffer for ion-exchange liquid chromatographic sample preparation sodium dilution buffer composed of $0.10 \mathrm{~g}$ of $\mathrm{N}_{3} \mathrm{Na}, 11.5 \mathrm{~g}$ of $\mathrm{NaCl}, 14 \mathrm{~g}$ of citric acid all diluted in 1 liter of water was used. Chemicals used as a part of the kits for urine biochemical parameters were glucose, pyrogallol red, creatinine and uric acid (Medesa s.r.o. Policka, Czech Republic) and urea. 4-Methylumbelliferyl phosphate was obtained from Tosoh Bioscience (Tokyo, Japan). As a derivatization agent used for ion-exchange chromatographic analyses, ninhydrin with methyl Cellosolve (Ingos, Prague, Czech Republic) and $\mathrm{SnCl}_{2}$ as a reduction agent were used. Washing solutions were prepared in Milli-Q water obtained using reverse osmosis equipment Aqual 25 (Aqual s.r.o., Brno, Czech Republic). The deionized water was further purified by using apparatus Direct-Q 3 UV Water Purification system equipped with a UV lamp from Millipore (Billerica, MA, USA). The resistance was established at $18 \mathrm{M} \Omega \cdot \mathrm{cm}^{-1}$. The $\mathrm{pH}$ was measured using the $\mathrm{pH}$ meter WTW inoLab (WTW, Weilheim, Germany).

Sample preparation for the determination of the urine amino acid profile. The urine sample $(500 \mu \mathrm{l})$ was pipetted into mineralization vials and mixed with $500 \mu \mathrm{l}$ of $35 \% \mathrm{HCl}$ and mineralized using the microwave equipment MW 3000 (Anton Paar, Graz, Austria) using parameters: Power 80; Ramp, 15 min; Hold, 90 min; Max, pressure 25 bar, Rotor XF100-6. The mineralized sample $(100 \mu \mathrm{l})$ was diluted with $900 \mu \mathrm{l}$ of dilution buffer and centrifuged using Centrifuge $5417 \mathrm{R}$ (Eppendorf, Hamburg, Germany) under the following conditions: temperature $4^{\circ} \mathrm{C}, 25,000 \mathrm{x}$ g for $20 \mathrm{~min}$. Subsequently, $500 \mu \mathrm{l}$ of the sample was diluted in $500 \mu \mathrm{l}$ of $0.6 \mathrm{M} \mathrm{NaOH}$ prior to analysis by ion-exchange chromatography.
Sample preparation for determination of sarcosine. The urine sample $(500 \mu \mathrm{l})$ was pipetted into a 96-well evaporation plate (Deepwell plate 96; Eppendorf AG) and evaporated by the nitrogen blow-down evaporator Ultravap 96 with spiral needles (Porvair Sciences Ltd., Leatherhead, UK). After this procedure, the sample was diluted with $500 \mu \mathrm{l}$ of dilution buffer and was subsequently used for analysis by ion-exchange chromatography.

Ion-exchange liquid chromatography. For determination of sarcosine, an ion-exchange liquid chromatography (Model AAA-400; Ingos) with post column derivatization by ninhydrin and an absorbance detector in visible light range (VIS) was used. A glass column with an inner diameter of 3.7 and length of $350 \mathrm{~mm}$ was filled manually with strong cation exchanger (Ostion LG ANB; Ingos) in sodium cycle with $\sim 12 \mu \mathrm{m}$ particles and $8 \%$ porosity. The column was thermostated at $60^{\circ} \mathrm{C}$. Double channel VIS detector with an inner cell of $5 \mu \mathrm{l}$ was set to two wavelengths: 440 and $570 \mathrm{~nm}$. Prepared solution of ninhydrin was stored under nitrogen atmosphere in the dark at $4^{\circ} \mathrm{C}$. Elution of amino acids was carried out by buffer containing $10.0 \mathrm{~g}$ of citric acid, $5.6 \mathrm{~g}$ of sodium citrate, and $8.36 \mathrm{~g}$ of natrium chloride per liter of solution ( $\mathrm{pH} 3.0$ ). The flow rate was $0.25 \mathrm{ml} \cdot \mathrm{min}^{-1}$. The reactor temperature was set to $120^{\circ} \mathrm{C}$.

Spectrophotometric analysis. For determination of all biochemical parameters a BS-400 automated spectrophotometer (Mindray, Shenzhen, China) was used. It is composed of cuvette space tempered to $37^{\circ} \mathrm{C}$, reagent space with a carousel for reagents (tempered to $4^{\circ} \mathrm{C}$ ), sample space with a carousel for preparation of samples and an optical detector. The cuvette contents are mixed by an automatic mixer including a stirrer immediately after addition of reagents or samples. Contamination is reduced due to its rinsing system. For detection itself, the following range of wavelengths were used: 340 , $380,412,450,505,546,570,605,660,700,740$ and $800 \mathrm{~nm}$.

Total protein was determined using the SKALAB CBT 600T kit (Skalab, Svitavy, Czech Republic), glucose was determined using a glucose assay (Greiner, Stuttgart, Germany), creatinine using a creatinine kit (Greiner), uric acid using a uric acid kit (Greiner), and urea using the Urea UV 5+1 assay (Greiner) according to the manufacturer's instructions.

Immunoenzymometric assay (IEMA). For analysis of PSA and fPSA in the sample of urine, IEMA was used. Measurement was carried out using the automated analyzer AIA 600 II (Tosoh Bioscience). Seventy microliters of urine sample was pipetted into the testing cup ST AIA-PACK PSAII obtained by Tosoh Bioscience containing lyophilized reagent (magnetic microbeads with murine anti-PSA and mouse anti-PSA conjugated with bovine alkaline phosphatase). Subsequently, the sample was incubated at $37^{\circ} \mathrm{C}$ for $10 \mathrm{~min}$. Non-bound antibodies were removed by washing solution (Tosoh Bioscience). Finally fluorogenic substrate (4-methylumbelliferyl phosphate) was added, and the intensity of the fluorescence for determination of the activity of the enzyme was measured.

Statistical analysis. The statistical analysis was carried out using several tests. All values in the present study are expressed 


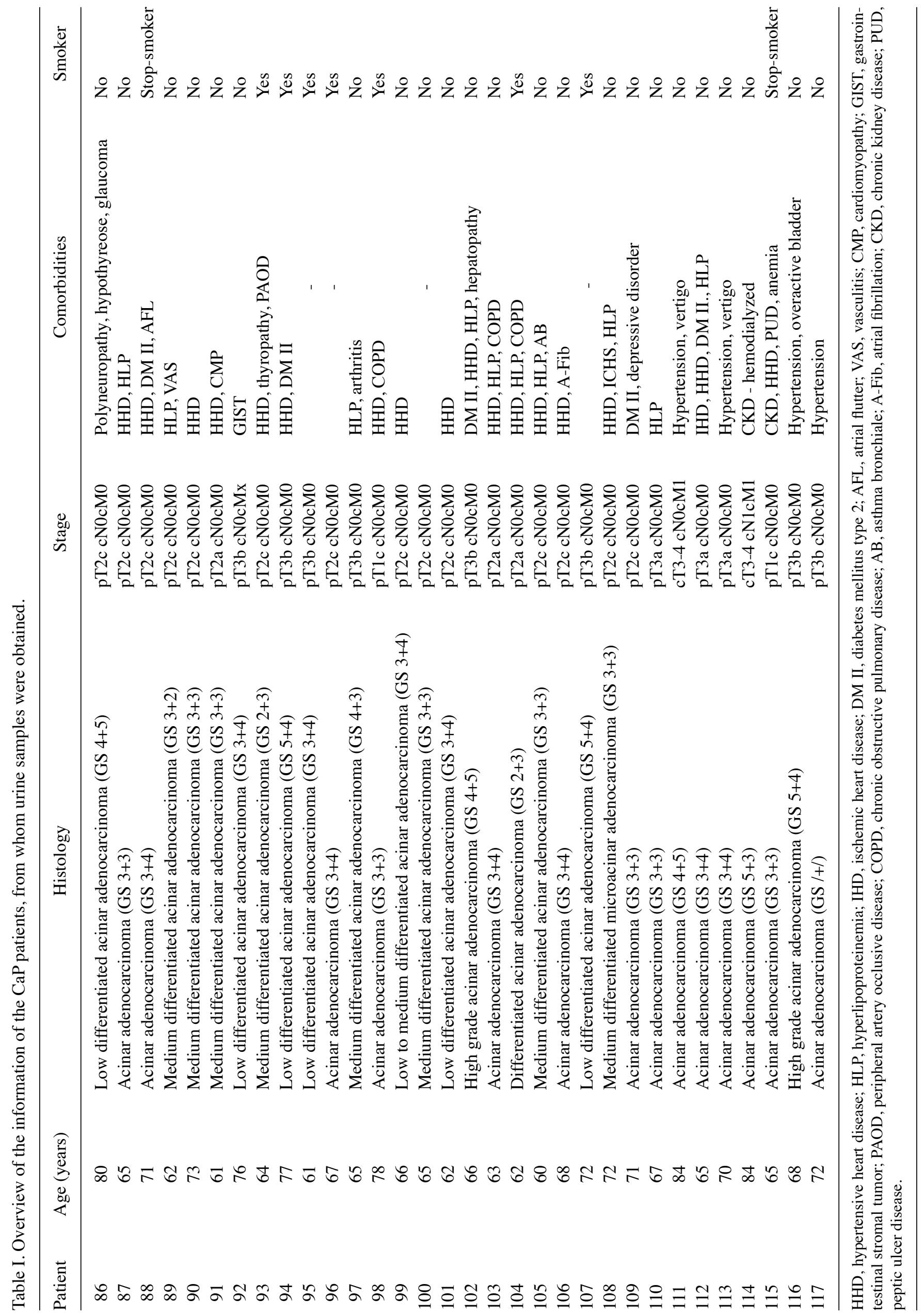




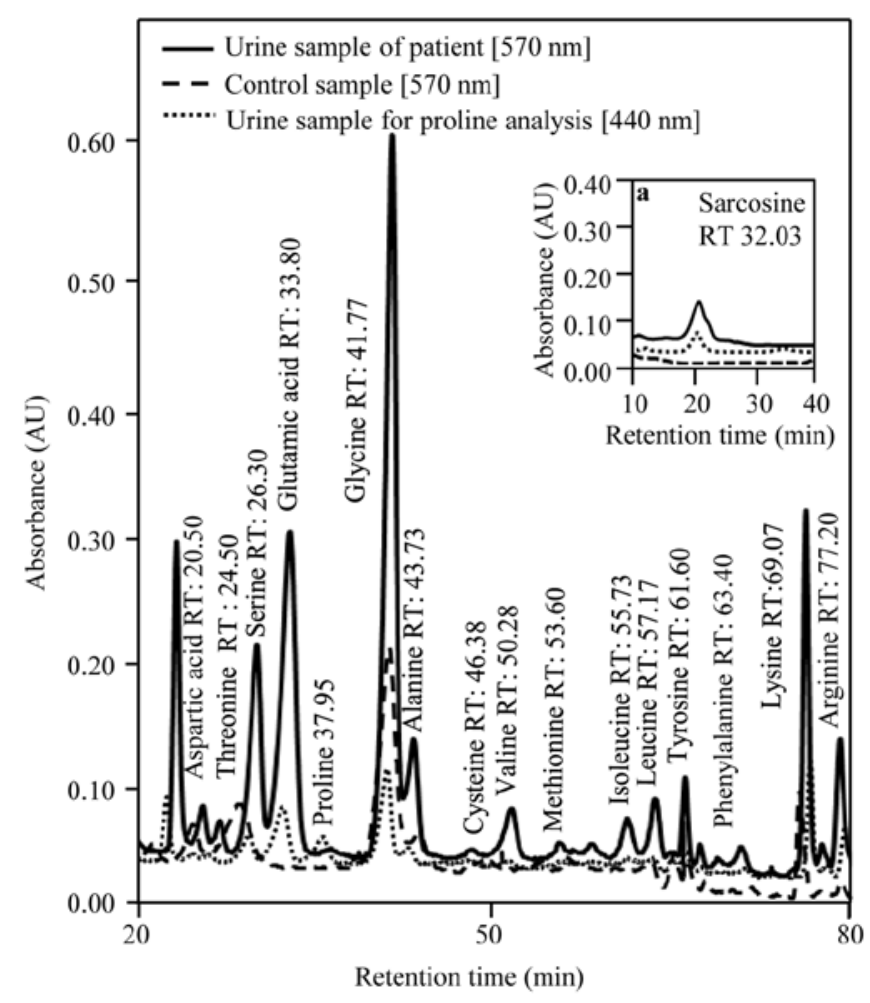

Figure 1. Overlay of chromatograms representing the urine amino acid profiles of - studied patients suffering from prostate cancer, - - control urine samples and ---- chosen patient samples analyzed at different wavelengths necessary for proline analysis. Increases in the amino acid content indicate the possible importance of amino acids in early $\mathrm{CaP}$ diagnosis. In inset (a), the results from the sarcosine analysis are indicated showing increased content of sarcosine in patient urine.

as means \pm SD. Firstly, data were checked for normality using Shapiro-Wilk test. t-tests were used to analyze differences between cases and controls. To outline dependencies between variables, hierarchical clustering on normalized data was used. A P-value $<0.05$ was considered to indicate a statistically significant result. Statistica Software 10 (StatSoft, Inc., Tulsa, OK USA) was used for analyses.

\section{Results and Discussion}

Amino acid determination in the urine samples. The purpose of the first part of the present study was to investigate the amino acid content in the urine of patients suffering from prostate carcinoma and to compare the results with the urine samples of the controls obtained from healthy individuals. Previously, it was reported that metabolism of amino acids is perturbed in tumor cells $(24,25)$, and urine amino acid profiles are consistently altered during tumor development $(20,26,27)$.

Proline. As shown in Fig. 1, the content of most of the analyzed amino acids in the urine obtained from the $\mathrm{CaP}$ patients was considerably increased. Proline was absent in the control samples while found in all patient samples at relatively high amounts. Proline is the only secondary amino acid incorporated into protein. It functions with its own distinct metabolic system, responsive to special metabolic requirements (28). POX/PRODH, the first enzyme in proline
Table II. Overview of the amino acid content in the urine of 32 prostate cancer patients and 32 controls.

\begin{tabular}{|c|c|c|c|c|c|}
\hline \multirow[b]{2}{*}{$\begin{array}{l}\text { Amino } \\
\text { acid }\end{array}$} & \multicolumn{2}{|c|}{ Cancer patients } & \multicolumn{2}{|c|}{ Healthy controls } & \multirow[b]{2}{*}{ P-value } \\
\hline & $\begin{array}{c}\text { Mean } \\
(\mu \mathrm{mol} / \mathrm{mmol})\end{array}$ & SD & $\begin{array}{c}\text { Mean } \\
(\mu \mathrm{mol} / \mathrm{mmol})\end{array}$ & SD & \\
\hline ASP & 3.07 & 2.69 & 0.74 & 2.28 & 0.000 \\
\hline THR & 1.72 & 2.12 & 0.08 & 2.92 & 0.013 \\
\hline SER & 3.43 & 0.72 & 3.28 & 1.66 & 0.640 \\
\hline GLU & 0.92 & 3.55 & 0.50 & 3.02 & 0.605 \\
\hline PRO & 4.79 & 1.96 & 0.31 & 0.55 & 0.000 \\
\hline GLY & 4.08 & 1.54 & 3.61 & 1.76 & 0.260 \\
\hline ALA & 2.65 & 1.15 & 2.36 & 1.72 & 0.433 \\
\hline CYS & 1.43 & 1.81 & 1.02 & 1.47 & 0.324 \\
\hline VAL & 1.14 & 1.61 & 0.72 & 1.45 & 0.280 \\
\hline MET & 0.75 & 1.51 & 0.02 & 1.17 & 0.025 \\
\hline ILE & 0.85 & 2.27 & 0.23 & 1.73 & 0.005 \\
\hline LEU & 1.58 & 2.11 & 0.17 & 1.54 & 0.000 \\
\hline TYR & 24.11 & 34.93 & 9.87 & 15.44 & 0.039 \\
\hline PHE & 9.16 & 25.50 & 20.70 & 83.89 & 0.459 \\
\hline HIS & 68.17 & 70.99 & 49.72 & 68.92 & 0.296 \\
\hline LYS & 32.82 & 67.23 & 18.62 & 34.28 & 0.291 \\
\hline ARG & 24.80 & 33.82 & 8.17 & 16.01 & 0.015 \\
\hline SAR & 23.49 & 18.96 & 0.00 & 0.00 & 0.000 \\
\hline
\end{tabular}

Asp, aspartic acid; Thr, threonine; Ser, serine; Glu, glutamic acid; Pro, proline; Gly, glycine; Ala, alanine; Cys, cysteine; Val, valine; Met, methionine; Ile, isoleucine; Leu, leucine; Tyr, tyrosine; Phe: phenylalanine; His, histidine; Lys, lysine; Arg, arginine; Sar, sarcosine; SD, standard deviation. All values are related to creatinine content.

catabolism, is induced by genotoxic (p53), inflammatory (PPAR $\gamma$ ) (29) and nutrient stress (glucose deprivation) (30). Polyak and colleagues (31) used adenoviral-p53 expression with subsequent, extensive analysis of gene expression. They found that 14 out of 7,202 genes were induced more than 7-fold. Proline oxidase was one of them and was marked as p53-induced gene-6 (PIG6). Proline catabolism catalyzed by POX produces proline-dependent radical oxygen species (ROS) specifically superoxides, resulting in proline-dependent apoptosis with potential to serve as a novel mitochondrial tumor suppressor $(32,33)$. In addition, Liu et al (34) showed that transcription factor MYC inhibits POX/PRODH expression and, thus, inhibits its function. microRNA miR-23b* an inhibitor of POX is highly expressed in different types of tumors $(35,36)$. Due to the lack of POX, the conversion of proline to pyrroline-5-carboxylate (P5C) is altered (37), and subsequently the amount of proline in urine is increased. Based on these facts and the results showing increased levels of proline compared to controls, proline appears to be a biomolecule with the potential to enlarge the spectrum of diagnostic tools for $\mathrm{CaP}$.

Sarcosine. The role of sarcosine as a potential biomarker of prostate carcinoma was confirmed. Sarcosine was determined in all patient urine samples (Fig. 1a). An elevated amount of sarcosine was probably caused by the overexpression of glycine 
Table III. Overview of the biochemical parameters and levels of ions and $\mathrm{pH}$ in urine samples of 32 prostate cancer patients and 32 controls.

\begin{tabular}{|c|c|c|c|c|c|}
\hline \multirow[b]{2}{*}{ Parameter } & \multicolumn{2}{|c|}{ Cancer patients } & \multicolumn{2}{|c|}{ Healthy controls } & \multirow[b]{2}{*}{ P-value } \\
\hline & Mean $(\mu \mathrm{mol} / \mathrm{mmol})$ & SD & Mean $(\mu \mathrm{mol} / \mathrm{mmol})$ & SD & \\
\hline $\mathrm{K}^{+}$ & 5.73 & 3.84 & 8.03 & 4.08 & 0.042 \\
\hline $\mathrm{Na}^{+}$ & 13.18 & 8.12 & 10.62 & 4.38 & 0.186 \\
\hline $\mathrm{Cl}^{-}$ & 9.12 & 6.98 & 9.98 & 4.14 & 0.607 \\
\hline Uric acid & 15.44 & $\mathbf{5 7 . 9 5}$ & 0.26 & 0.10 & 0.026 \\
\hline Urea & 38.66 & 18.42 & 23.79 & 12.26 & 0.002 \\
\hline PSA & 4.93 & 7.52 & 0.00 & 0.00 & 0.000 \\
\hline Glucose & 0.05 & 0.13 & 0.02 & 0.02 & 0.341 \\
\hline Pyrogallol & 0.08 & 0.21 & 0.00 & 0.00 & 0.081 \\
\hline fPSA & 17.46 & 2.12 & 0.00 & 0.00 & 0.000 \\
\hline $\mathrm{pH}$ & 6.05 & 0.75 & 6.49 & 0.32 & 0.058 \\
\hline Creatinine & 15.04 & 4.74 & 9.57 & 18.94 & 0.019 \\
\hline
\end{tabular}

Levels of $\mathrm{K}^{+}, \mathrm{Na}^{+}, \mathrm{Cl}^{-}$, uric acid, urea, PSA, glucose, pyrogallol and fPSA were measured in $\mathrm{mmol} / \mathrm{mmol}$ of creatinine; creatinine was measured in $\mathrm{mmol} \cdot \mathrm{l}^{-1}$. Statistical significant differences between patients and controls were observed for levels of $\mathrm{K}^{+}$ions, uric acid, urea and creatinine and are indicated in bold print. SD, standard deviation. FPSA, free PSA.

$N$-methyl transferase (GNMT), cleaving glycine to sarcosine (23). Overexpression of GNMT, encoded by the GNMT gene, was previously observed in patients suffering from CaP (38). The expression of GNMT induced in this manner leads to elevated synthesis of GNMT that subsequently contributes to the regulation of the levels of S-adenosylmethionine (SAM), subsequently affecting the gene expression by influencing DNA methylation (38). The role of SAM is to transfer the methyl groups and to use them for formation of many essential compounds as creatine or phosphatidylcholine. It has been previously reported that the increased conflux of GNMT results in the elevated formation of sarcosine through increased utilization of SAM (39). The absence of sarcosine in control samples indicates that it is applicable for diagnosis, due to the reduction in false-positive or negative results (23) similar to proline.

Total amino acid content. Furthermore, the basic statistical comparison of amino acid content in the cases and controls was carried out, and the results are summarized in Table II. Values measured were recalculated to urinary creatinine concentration. From these means, standard deviations and P-values were calculated. All amino acids were significantly increased except for phenylalanine amounts.

Statistical significant results were observed for aspartic acid, threonine, methionine, isoleucine, leucine, tyrosine and arginine. Levels of sarcosine and proline in the controls were negligible (mean $0.31 \mu \mathrm{mol} / \mathrm{mmol}$ of creatinine for proline) or at zero (absent or below the limit of detection) for sarcosine. Levels of these biomolecules found in samples obtained from the patients included proline $(4.79 \mu \mathrm{mol} / \mathrm{mmol}$ of creatinine) and sarcosine (23.49 $\mu \mathrm{mol} / \mathrm{mmol}$ of creatinine) (Table II). These findings support possible utilization of these biomolecules for diagnosis. Relative standard deviation of proline $(1.96 \%)$ indicated relatively similar values in all cases.
In contrast, the relative standard deviations for sarcosine showed higher scatter (18.96\%). This was probably caused by the different stages of carcinomas diagnosed in the patients. Levels of other amino acids were altered when compared to the control samples, supporting the general theory concerning the perturbation of tumor cell metabolism $(24,25)$.

Biochemical parameters of the urine samples. Using various spectrophotometric methods, the concentrations of $\mathrm{K}^{+}, \mathrm{Na}^{+}$, $\mathrm{Cl}^{-}$, uric acid, urea, PSA, glucose, total proteins (pyrogallol method), fPSA, creatinine and $\mathrm{pH}$ were measured simultaneously with the amino acids (Table III). All parameters were related to creatinine content and subjected to basic statistical analysis. Statistically significant differences between patients and controls were observed for levels of $\mathrm{K}^{+}$ions, uric acid, urea and creatinine. Serum PSA is currently the most widely used method for $\mathrm{CaP}$ diagnosis (40-42). Detecting cancer using low PSA values risks excessive unnecessary biopsies and the detection of clinically insignificant disease. Although PSA has high diagnostic value in the early diagnosis of $\mathrm{CaP}$, there is a considerable overlap of PSA values between various stages of prostate cancer, and decreasing levels cannot be used to evaluate treatment efficacy in all patients (43). Based on this fact, it has been suggested that the ratio of fPSA/tPSA may improve the specificity of PSA for the diagnosis of CaP (44). As shown in Table III, the levels of both PSA and fPSA were below the detection limits in the controls. In patients, the levels were $4.93 \mu \mathrm{mol} / \mathrm{mmol}$ of creatinine and $17.46 \mu \mathrm{mol} / \mathrm{mmol}$ of creatinine for PSA and fPSA, respectively, with relative standard deviations of $7.52 \%$ for PSA and $2.12 \%$ for PPSA.

Androgen deprivation therapy (ADT) was found to delay disease progression in the management of advanced $\mathrm{CaP}$. Nevertheless, the suppression of testosterone associated with ADT may often lead to hypogonadal conditions with harmful effects on renal function leading to acute kidney 


\begin{tabular}{|c|c|c|c|c|c|c|c|c|c|c|c|c|c|c|c|c|c|c|}
\hline & Asp & Thr & Ser & Gly & Pro & Glu & Ala & Cys & Val & Met & Ile & Leu & Tyr & Phe & His & Lys & Arg & Sar \\
\hline Asp & 1.00 & 0.91 & 0.60 & 0.91 & 0.74 & 0.63 & 0.35 & 0.47 & 0.70 & 0.58 & 0.69 & 0.93 & 0.46 & 0.21 & 0.48 & 0.46 & 0.69 & -0.07 \\
\hline Thr & 0.91 & 1.00 & 0.75 & 0.85 & 0.53 & 0.67 & 0.43 & 0.51 & 0.69 & 0.67 & 0.73 & 0.86 & 0.50 & 0.34 & 0.55 & 0.51 & 0.59 & -0.04 \\
\hline Ser & 0.60 & 0.75 & 1.00 & 0.64 & 0.17 & 0.55 & 0.36 & 0.42 & 0.67 & 0.42 & 0.45 & 0.54 & 0.15 & 0.33 & 0.46 & 0.26 & 0.32 & 0.03 \\
\hline Gly & 0.91 & 0.85 & 0.64 & 1.00 & 0.48 & 0.62 & 0.31 & 0.49 & 0.72 & 0.49 & 0.58 & 0.83 & 0.41 & 0.29 & 0.44 & 0.42 & 0.61 & -0.35 \\
\hline Pro & 0.74 & 0.53 & 0.17 & 0.48 & 1.00 & 0.42 & 0.21 & 0.16 & 0.37 & 0.34 & 0.53 & 0.73 & 0.34 & -0.06 & 0.34 & 0.29 & 0.65 & 0.25 \\
\hline Glu & 0.63 & 0.67 & 0.55 & 0.62 & 0.42 & 1.00 & 0.03 & 0.24 & 0.52 & 0.41 & 0.42 & 0.72 & 0.53 & 0.33 & 0.68 & 0.28 & 0.45 & -0.10 \\
\hline Ala & 0.35 & 0.43 & 0.36 & 0.31 & 0.21 & 0.03 & 1.00 & 0.50 & 0.46 & 0.67 & 0.40 & 0.36 & 0.35 & 0.24 & 0.06 & 0.46 & 0.43 & 0.02 \\
\hline Cys & 0.47 & 0.51 & 0.42 & 0.49 & 0.16 & 0.24 & 0.50 & 1.00 & 0.56 & 0.66 & 0.58 & 0.51 & 0.44 & 0.31 & 0.07 & 0.54 & 0.42 & -0.07 \\
\hline Val & 0.70 & 0.69 & 0.67 & 0.72 & 0.37 & 0.52 & 0.46 & 0.56 & 1.00 & 0.55 & 0.68 & 0.67 & 0.29 & 0.24 & 0.49 & 0.25 & 0.49 & -0.12 \\
\hline Met & 0.58 & 0.67 & 0.42 & 0.49 & 0.34 & 0.41 & 0.67 & 0.66 & 0.55 & 1.00 & 0.57 & 0.59 & 0.60 & 0.18 & 0.29 & 0.58 & 0.50 & 0.00 \\
\hline Ile & 0.69 & 0.73 & 0.45 & 0.58 & 0.53 & 0.42 & 0.40 & 0.58 & 0.68 & 0.57 & 1.00 & 0.76 & 0.44 & 0.27 & 0.41 & 0.44 & 0.58 & -0.01 \\
\hline Leu & 0.93 & 0.86 & 0.54 & 0.83 & 0.73 & 0.72 & 0.36 & 0.51 & 0.67 & 0.59 & 0.76 & 1.00 & 0.57 & 0.34 & 0.51 & 0.53 & 0.70 & -0.07 \\
\hline Tyr & 0.46 & 0.50 & 0.15 & 0.41 & 0.34 & 0.53 & 0.35 & 0.44 & 0.29 & 0.60 & 0.44 & 0.57 & 1.00 & 0.20 & 0.18 & 0.43 & 0.59 & -0.06 \\
\hline Phe & 0.21 & 0.34 & 0.33 & 0.29 & -0.06 & 0.33 & 0.24 & 0.31 & 0.24 & 0.18 & 0.27 & 0.34 & 0.20 & 1.00 & 0.11 & 0.32 & 0.10 & -0.10 \\
\hline His & 0.48 & 0.55 & 0.46 & 0.44 & 0.34 & 0.68 & 0.06 & 0.07 & 0.49 & 0.29 & 0.41 & 0.51 & 0.18 & 0.11 & 1.00 & 0.32 & 0.34 & 0.02 \\
\hline Lys & 0.46 & 0.51 & 0.26 & 0.42 & 0.29 & 0.28 & 0.46 & 0.54 & 0.25 & 0.58 & 0.44 & 0.53 & 0.43 & 0.32 & 0.32 & 1.00 & 0.59 & -0.02 \\
\hline Arg & 0.69 & 0.59 & 0.32 & 0.61 & 0.65 & 0.45 & 0.43 & 0.42 & 0.49 & 0.50 & 0.58 & 0.70 & 0.59 & 0.10 & 0.34 & 0.59 & 1.00 & -0.04 \\
\hline Sar & 0.07 & -0.04 & 0.03 & -0.35 & 0.25 & -0.10 & 0.02 & -0.07 & -0.12 & 0.00 & -0.01 & -0.07 & -0.06 & -0.10 & 0.02 & -0.02 & -0.04 & 1.00 \\
\hline
\end{tabular}

Figure 2. Correlation between amino acid amounts, represented by their correlation coefficients. A positive correlation is indicated in bold print, a negative correlation with italics, insignificant correlation is indicated with normal font. Sarcosine was found to be negatively correlated with most of the amino acids. The most significant dependencies were observed between sarcosine and proline and glutamic acid.

injury $(45,46)$. Deteriorated kidney tissue loses its capability to maintain its naturally functions resulting in disturbances in urine electrolytes (Table III). We found $5.73 \mu \mathrm{mol} / \mathrm{mmol}$ of creatinine of $\mathrm{K}^{+}$ions, and their concentrations in the controls were established at $8.03 \mu \mathrm{mol} / \mathrm{mmol}$ of creatinine. The downward trend observed in $\mathrm{K}^{+}$ions was also noted in $\mathrm{Cl}^{-}$ions, but at a much lower level (mean $9.12 \mu \mathrm{mol} / \mathrm{mmol}$ of creatinine for patients compared to $9.98 \mu \mathrm{mol} / \mathrm{mmol}$ of creatinine measured in the controls). An opposite upward trend was observed in $\mathrm{Na}^{+}$ions (mean $13.18 \mu \mathrm{mol} / \mathrm{mmol}$ of creatinine in patients and $10.62 \mu \mathrm{mol} / \mathrm{mmol}$ of creatinine in controls). Levels of different ions in the urine of prostate cancer patients are not well understood, mainly due to problems regarding other associated health complications, significantly affecting the urine electrolyte composition, such as inflammation. Hence, these factors prevent their utilization as auxiliary diagnostic markers of $\mathrm{CaP}$.

Uric acid is an important antioxidant and free radical scavenger formed in the body as a product of purine degradation. Several studies have reported that the uric acid level is depleted during tumor development $(47,48)$. In contrast, uric acid may be increased due to cancer therapy, such as by chemotherapy or irradiation during treatment. Kolonel et al (50) carried out comprehensive analysis of different types of cancer (prostate, stomach, colorectal, lung, urinary bladder and leukemia). There were no significant associations between the type of cancer and uric acid level except for prostate cancer. In prostate carcinoma a positive association was found. Similarly we observed distinct differences in the content of uric acid (mean $15.44 \mu \mathrm{mol} / \mathrm{mmol}$ of creatinine in patients and $0.26 \mu \mathrm{mol} / \mathrm{mmol}$ of creatinine in controls; Table III). Our results confirmed the implication of uric acid in cancer pathogenesis and indicates good accessibility of uric acid as a possible additional diagnostic marker of $\mathrm{CaP}$. This compound can be measured simply and at low costs, and with the possibility of method automation. In patients suffering from $\mathrm{CaP}$, higher levels of urea are observed. Values of $38.66 \mu \mathrm{mol} / \mathrm{mmol}$ of creatinine for patients compared to controls (mean $23.79 \mu \mathrm{mol} / \mathrm{mmol}$ of creatinine; Table III) again indicate impaired functioning of the kidneys. Higher levels of urea excreted in the urine may potentially serve as a marker of acute kidney injury (AKI), commonly observed in patients undergoing anticancer therapy. Koyner et al (51) showed that fractional excretion of urea is not able to be used to detect a difference in AKI course, severity, and outcomes, but on the other hand may serve as an early detection marker of kidney injury, a frequent complication in $\mathrm{CaP}$ patients. It clearly follows from the results obtained that patients were affected by kidney function deterioration. For this reason we also noted higher levels of creatinine, a marker of the correct glomerular filtration rate of the kidney (52), ordinarily used for standardization of urine waste substances (mean $15.04 \mu \mathrm{mol} / 1$ in cases compared to $9.57 \mu \mathrm{mol} / 1$ in control samples; Table III).

For glucose content, only minimal differences with no statistical significance were found as well as in total proteins determined using pyrogallol red (Table III). Higher levels of proteins in urine (mean $0.08 \mu \mathrm{mol} / \mathrm{mmol}$ of creatinine compared to $0.00 \mu \mathrm{mol} / \mathrm{mmol}$ of creatinine in control samples) were probably caused by the presence of chronic inflammation accompanying prostate cancer. Inflammation has been proposed as one of the potential carcinogens for $\mathrm{CaP}$. It was shown that inflammation may be found in prostate biopsy tissues, prostatectomy specimens, and chips from transurethral resection of the prostate (53). Minimal differences were observed also in the $\mathrm{pH}$ of the urine, but generally urine samples from patients with prostate carcinoma showed 


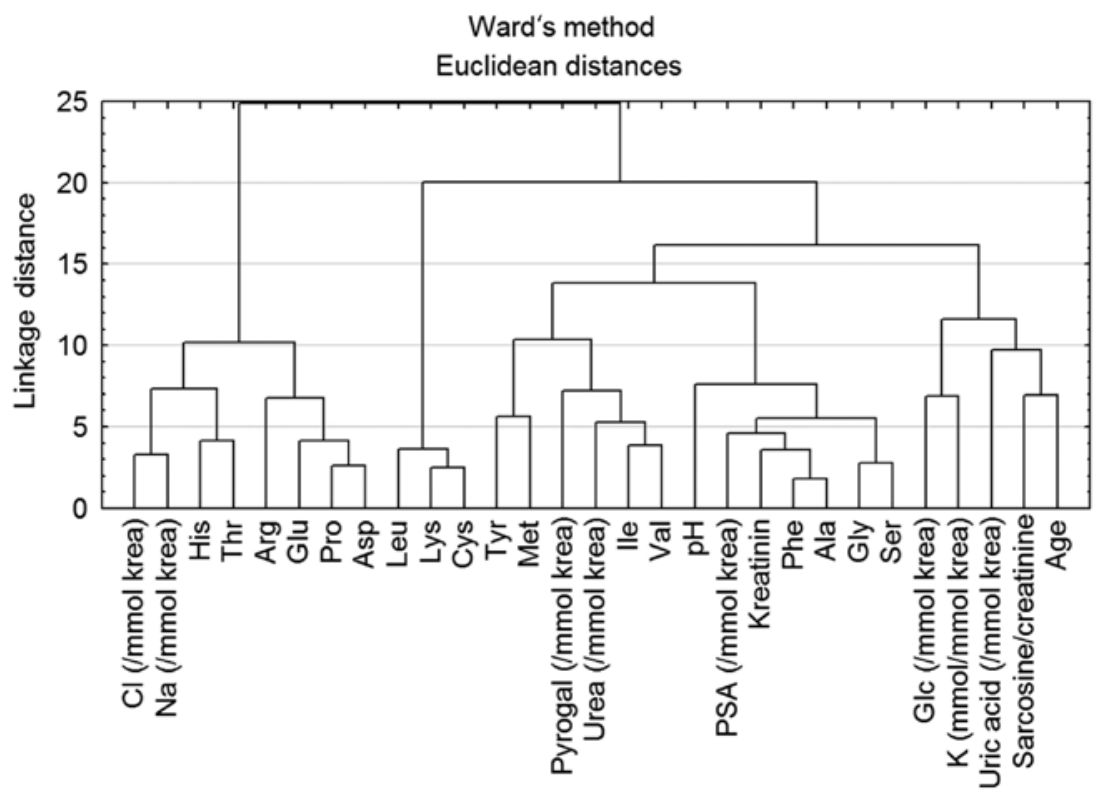

Figure 3. Dendrogram showing the cluster analysis between the different parameters. Note closely clustered sarcosine with age and $\mathrm{Na}^{+}$with $\mathrm{Cl}^{-}$.

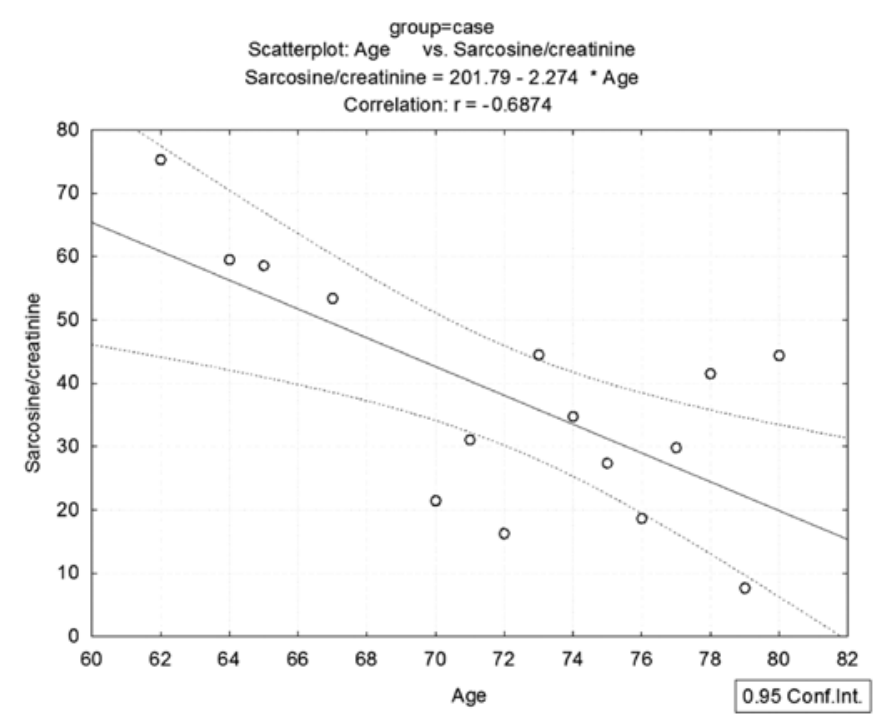

Figure 4. Evidence of the sarcosine dependence on age as indicated from the dendrogram from the cluster analysis. The negative correlation between age and sarcosine is indicated.

lower $\mathrm{pH}$ values (mean 6.05) when compared with the control samples (mean 6.49). Slightly acidic pH corresponds with higher levels of proteins and uric acid; nevertheless, this value is still within the physiologic range (54).

Furthermore, we carried out a correlation analysis for each amino acid determined in the urine samples from the $\mathrm{CaP}$ patients. From the values obtained from previous measurements, the correlation coefficients were prepared and subsequently compared to each other (Fig. 2). A positive correlation is highlighted in bold print, negative in italics, no correlation in normal font. As shown in Fig. 2, for sarcosine, instead of serine, alanine, methionine and histidine, negative correlations were observed. In contrast, when comparing sarcosine with proline, a positive correlation was noted. Negative correlations indicate an increased sarcosine amount in urine in comparison with other amino acids. The only negative correlation with statistical significance was observed in the case of glycine. On the biochemical basis of sarcosine formation during prostate carcinoma development this phenomenon is caused due to glycine degradation at the expense of sarcosine creation. Montrose et al (55) previously confirmed that within tumor tissue, sarcosine dehydrogenase (SARDH), the enzyme which converts sarcosine to glycine, is dysregulated. On the other hand, enzymes generating sarcosine from glycine, glycine $N$-methyl transferase (GNMT) and dimethylglycine dehydrogenase (DMGDH) are elevated in $\mathrm{CaP}$ patients (56). This process may explain the increases in sarcosine levels in urine. A high positive correlation of proline was probably random and caused by high increases in proline levels in the patients when compared to sarcosine.

Cluster analysis of all measured urine parameters. For revealing the correlation between all parameters, Ward's method of hierarchical cluster analysis was carried out (Fig. 3). Because of the different units for each parameter, the data were standardized to average zero and standard deviation 1 . Due to this fact the dimensionless y-axis - linkage distance was used. From the dendrogram, two main dependencies may be observed. First one is the dependence of $\mathrm{Na}^{+}$and $\mathrm{Cl}^{-}$ions. As mentioned above, the concentration of ions in urine electrolytes is highly influenced by kidney conditions and associated diseases. Due to this fact, the correlation of these two parameters was difficult to evaluate. The dependence of sarcosine on age was more significant (Fig. 3). Although the significant dependence was evident, in order to obtain more detailed insight into this correlation it was necessary to perform a correlation test. Statistical analysis revealed a negative dependence between sarcosine and age ( $r=-0.068$ ) (Fig. 4). Sarcosine was originally proven to be a mechanistic biomarker of mainly aggressive prostate cancer (19). In accordance with this fact, levels of sarcosine are decreased in elderly patients who have a higher 
probability to suffer from non-aggressive prostate carcinoma with a lower ability to produce sarcosine due to dysregulation of the enzymes producing and catabolizing sarcosine (57). The current hypothesis is that most aged men have prostate cancer, and they have cells in their prostates that if observed on a needle biopsy would be diagnosed as prostate cancer (58). This fact is supported by the study of Powell et al (59) showing that prostate carcinoma can be found in $50 \%$ of males 50 years of age, and $70-80 \%$ of men over the age of 70 years, dying from non-prostate cancer-related causes. These lesions are called 'microscopic' or 'latent' foci of prostate cancer, typical of their small size, non-progressiveness, clinically insignificance and rare detection through routine prostate cancer screening. These properties are fundamentally different from aggressive tumors in most cases detected in younger men producing more sarcosine when compared to the non-aggressive forms of the tumors.

In conclusion, in the present study various urine parameters were compared between patients suffering from prostate carcinoma and healthy individuals. Our results indicate that urine sarcosine, proline, uric acid and PSA may serve as a set of non-invasive, rapid, screening panel for $\mathrm{CaP}$ examination. Searching for new non-invasive markers of prostate carcinoma is still a great challenge for researchers. PSA achieves relatively excellent results, but specificity could be enhanced. For this reason we searched for correlations between well-known substances with potential for routine analysis in urine samples. We found one profile that may be utilized with relatively high meaningful evaluation from urine samples. This profile includes analysis of the widely studied amino acid sarcosine, amino acid proline, PSA and uric acid. Higher levels of these substances were not found in control samples obtained from health individuals, but were greatly increased in the samples from $\mathrm{CaP}$ patients. Inclusion of these analytes to a test panel could increase the specificity of prostate carcinoma diagnosis. Other parameters such as urea, $\mathrm{K}^{+}$ions or other amino acids were also altered, but their presence in control samples hindered their utilization for diagnosis. Moreover, their increased levels may rather indicate kidney injury following treatment. Analysis of the above mentioned substances with potential to serve as non-invasive biomarkers can be achieved at a relatively low cost, but the utilization in clinical practice requires examination of a larger cohort of patients.

\section{Acknowledgements}

The present study was financially supported by the CEITEC CZ.1.05/1.1.00/02.0068 and the project for conceptual development of research organization 00064203.

\section{References}

1. Siegel R, Naishadham D and Jemal A: Cancer statistics, 2013 CA Cancer J Clin 63: 11-30, 2013.

2. Ding ZH, Wu CJ, Chu GC, et al: SMAD4-dependent barrier constrains prostate cancer growth and metastatic progression. Nature 470: 269-273, 2011

3. Boyle P and Ferlay J: Cancer incidence and mortality in Europe, 2004. Ann Oncol 16: 481-488, 2005.

4. Armstrong AJ, Eisenberger MA, Halabi S, et al: Biomarkers in the management and treatment of men with metastatic castrationresistant prostate cancer. Eur Urol 61: 549-559, 2012.
5. Prensner JR, Rubin MA, Wei JT and Chinnaiyan AM: Beyond PSA: the next generation of prostate cancer biomarkers. Sci Transl Med 4: 1-12, 2012.

6. Lattanzi J, McNeely S, Hanlon A, Das I, Schultheiss TE and Hanks GE: Daily CT localization for correcting portal errors in the treatment of prostate cancer. Int J Radiat Oncol Biol Phys 41: 1079-1086, 1998.

7. van Vugt HA, Roobol MJ, Busstra M, et al: Compliance with biopsy recommendations of a prostate cancer risk calculator. BJU Int 109: 1480-1488, 2012.

8. Schoder H and Larson SM: Positron emission tomography for prostate, bladder, and renal cancer. Semin Nucl Med 34: 274-292, 2004.

9. FukushimaK, Satoh T,Baba S and Yamashita K: $\alpha$ 1,2-Fucosylated and $\beta$ - $N$-acetylgalactosaminylated prostate-specific antigen as an efficient marker of prostatic cancer. Glycobiology 20: 452-460, 2010.

10. Page ST, Hirano L, Gilchriest J, et al: Dutasteride reduces prostate size and prostate-specific antigen in older hypogonadal men with benign prostatic hyperplasia undergoing testosterone replacement therapy. J Urol 186: 191-197, 2011.

11. Zitka O, Cernei N, Heger Z, et al: Microfluidic chip coupled with modified paramagnetic particles for sarcosine isolation in urine. Electrophoresis 34: 2639-2647, 2013.

12. Berger MF, Lawrence MS, Demichelis F, et al: The genomic complexity of primary human prostate cancer. Nature 470: 214-220, 2011.

13. Cao DL, Ye DW, Zhang HL, Zhu Y, Wang YX and Yao XD: A multiplex model of combining gene-based, protein-based, and metabolite-based with positive and negative markers in urine for the early diagnosis of prostate cancer. Prostate 71: 700-710, 2011.

14. Rigau M, Morote J, Mir MC, et al: PSGR and PCA3 as biomarkers for the detection of prostate cancer in urine. Prostate 70: 1760-1767, 2010

15. Crawford ED, Rove KO, Trabulsi EJ, et al: Diagnostic performance of PCA3 to detect prostate cancer in men with increased prostate specific antigen: a prospective study of 1,962 cases. J Urol 188: 1726-1731, 2012.

16. Jamaspishvili T, Kral M, Khomeriki I, Student V, Kolar Z and Bouchal J: Urine markers in monitoring for prostate cancer. Prostate Cancer Prostatic Dis 13: 12-19, 2010.

17. Pin E, Fredolini C and Petricoin EF: The role of proteomics in prostate cancer research: biomarker discovery and validation. Clin Biochem 46: 524-538, 2013.

18. Vesprini D, Liu S and Nam R: Predicting high risk disease using serum and DNA biomarkers. Curr Opin Urol 23: 252-260, 2013.

19. Sreekumar A, Poisson LM, Rajendiran TM, et al: Metabolomic profiles delineate potential role for sarcosine in prostate cancer progression. Nature 457: 910-914, 2009.

20. Cavaliere B, Macchione B, Monteleone M, Naccarato A, Sindona $\mathrm{G}$ and Tagarelli A: Sarcosine as a marker in prostate cancer progression: a rapid and simple method for its quantification in human urine by solid-phase microextraction-gas chromatography-triple quadrupole mass spectrometry. Anal Bioanal Chem 400: 2903-2912, 2011.

21. Petersen LF, Brockton NT, Bakkar A, et al: Elevated physiological levels of folic acid can increase in vitro growth and invasiveness of prostate cancer cells. BJU Int 109: 788-795, 2012.

22. Lucarelli G, Fanelli M, Larocca AMV, et al: Serum sarcosine increases the accuracy of prostate cancer detection in patients with total serum PSA less than $4.0 \mathrm{ng} / \mathrm{ml}$. Prostate 72: 1611-1621, 2012.

23. Cernei N, Heger Z, Gumulec J, et al: Sarcosine as a potential prostate cancer biomarker: a review. Int J Mol Sci 14: 13893-13908, 2013.

24. Chen JL, Tang HQ, Hu JD, Fan J, Hong J and Gu JZ: Metabolomics of gastric cancer metastasis detected by gas chromatography and mass spectrometry. World J Gastroenterol 16: 5874-5880, 2010.

25. Hirayama A, Kami K, Sugimoto M, et al: Quantitative metabolome profiling of colon and stomach cancer microenvironment by capillary electrophoresis time-of-flight mass spectrometry. Cancer Res 69: 4918-4925, 2009.

26. Slupsky CM, Steed H, Wells TH, et al: Urine metabolite analysis offers potential early diagnosis of ovarian and breast cancers. Clin Cancer Res 16: 5835-5841, 2010.

27. Kim K, Taylor SL, Ganti S, Guo LN, Osier MV and Weiss RH: Urine metabolomic analysis identifies potential biomarkers and pathogenic pathways in kidney cancer. OMICS 15: 293-303, 2011. 
28. Phang JM: The regulatory functions of proline and pyrroline5-carboxylic acid. Curr Top Cell Regul 25: 91-132, 1985.

29. Pandhare J, Cooper SK and Phang JM: Proline oxidase, a proapoptotic gene, is induced by troglitazone: evidence for both peroxisome proliferator-activated receptor $\gamma$-dependent and -independent mechanisms. J Biol Chem 281: 2044-2052, 2006.

30. Pandhare J, Donald SP, Cooper SK and Phang JM: Regulation and function of proline oxidase under nutrient stress. J Cell Biochem 107: 759-768, 2009.

31. Polyak K, Xia Y, Zweier K, Kinzler W and Vogelstein B: A model for p53-induced apoptosis. Nature 389: 300-305, 1997.

32. Donald SP, Sun XY, Hu CAA, et al: Proline oxidase, encoded by $\mathrm{p} 53$-induced gene- 6 , catalyzes the generation of prolinedependent reactive oxygen species. Cancer Res 61: 1810-1815, 2001.

33. Liu Y, Borchert GL, Surazynski A, Hu CA and Phang JM Proline oxidase activates both intrinsic and extrinsic pathways for apoptosis: the role of ROS/superoxides, NFAT and MEK ERK signaling. Oncogene 25: 5640-5647, 2006.

34. Liu W, Le A, Hancock C, et al: Reprogramming of proline and glutamine metabolism contributes to the proliferative and metabolic responses regulated by oncogenic transcription factor c-MYC. Proc Natl Acad Sci USA 109: 8983-8988, 2012.

35. Phang JM and Liu W: Proline metabolism and cancer. Front Biosci 17: 1835-1845, 2012.

36. Liu W, Zabirnyk O, Wang $\mathrm{H}$, et al: miR-23b* targets proline oxidase, a novel tumor suppressor protein in renal cancer. Oncogene 29: 4914-4924, 2010.

37. Liu Y, Borchert GL, Surazynski A and Phang JM: Proline oxidase, a p53-induced gene, targets $\mathrm{COX}-2 / \mathrm{PGE}_{2}$ signaling to induce apoptosis and inhibit tumor growth in colorectal cancers. Oncogene 27: 6729-6737, 2008.

38. Ianni M, Porcellini E, Carbone I, et al: Genetic factors regulating inflammation and DNA methylation associated with prostate cancer. Prostate Cancer Prostatic Dis 16: 56-60, 2013.

39. Luka Z, Cerone R, Phillips JA, Mudd SH and Wagner C: Mutations in human glycine N-methyltransferase give insights into its role in methionine metabolism. Hum Genet 110: 68-74, 2002.

40. Pelzer AE, Volgger H, Bektic J, et al: The effect of percentage free prostate-specific antigen (PSA) level on the prostate cancer detection rate in a screening population with low PSA levels. BJU Int 96: 995-998, 2005.

41. Sirovich BE, Schwartz LM and Woloshin S: Screening men for prostate and colorectal cancer in the United States: does practice reflect the evidence? JAMA 289: 1414-1420, 2003.

42. Seo HS and Lee NK: Predictors of PSA screening among men over 40 years of age who had ever heard about PSA. Korean J Urol 51: 391-397, 2010.

43. Demers LM, Costa L, Chinchilli VM, Gaydos L, Curley E and Lipton A: Biochemical markers of bone turnover in patients with metastatic bone disease. Clin Chem 41: 1489-1494, 1995.

44. Catalona WJ, Partin AW, Slawin KM, et al: Use of the percentage of free prostate-specific antigen to enhance differentiation of prostate cancer from benign prostatic disease: a prospective multicenter clinical trial. JAMA 279: 1542-1547, 1998.
45. Lapi F, Azoulay L, Niazi T, Yin H, Benayoun S and Suissa S: Androgen deprivation therapy and risk of acute kidney injury in patients with prostate cancer. JAMA 310: 289-296, 2013.

46. Nariculam J, Murphy DG, Jenner C, et al: Nephrostomy insertion for patients with bilateral ureteric obstruction caused by prostate cancer. Br J Radiol 82: 571-576, 2009.

47. Panis C, Victorino VJ, Herrera ACSA, et al: Differential oxidative status and immune characterization of the early and advanced stages of human breast cancer. Breast Cancer Res Treat 133: 881-888, 2012.

48. Xu XL, Rao GS, Groh V, et al: Major histocompatibility complex class I-related chain A/B (MICA/B) expression in tumor tissue and serum of pancreatic cancer: role of uric acid accumulation in gemcitabine-induced MICA/B expression. BMC Cancer 11: 194 2011.

49. Burgaz S, Torun M, Yardim S, Sargin H, Orman MN and Ozdamar NY: Serum carotenoids and uric acid levels in relation to cancer. J Clin Pharm Ther 21: 331-336, 1996.

50. Kolonel LN, Yoshizawa C, Nomura AMY and Stemmermann GN: Relationship of serum uric-acid to cancer occurrence in a prospective male cohort. Cancer Epidemiol Biomarkers Prev 3: 225-228, 1994.

51. Koyner JL, Vaidya VS, Bennett MR, et al: Urinary biomarkers in the clinical prognosis and early detection of acute kidney injury. Clin J Am Soc Nephrol 5: 2154-2165, 2010.

52. Chen $\mathrm{CH}$ and Lin MS: A novel structural specific creatinine sensing scheme for the determination of the urine creatinine. Biosens Bioelectron 31: 90-94, 2012.

53. Elsberger B, Lankston L, McMillan DC, Underwood MA and Edwards J: Presence of tumoural C-reactive protein correlates with progressive prostate cancer. Prostate Cancer Prostatic Dis 14: 122-128, 2011.

54. Grases F, Costa-Bauza A and Prieto RM: Renal lithiasis and nutrition. Nutr J 5: 1-7, 2006.

55. Montrose DC, Zhou XK, Kopelovich L, et al: Metabolic profiling, a noninvasive approach for the detection of experimental colorectal neoplasia. Cancer Prev Res 5: 1358-1367, 2012.

56. Green T, Chen XF, Ryan S, Asch AS and Ruiz-Echevarria MJ: TMEFF2 and SARDH cooperate to modulate one-carbon metabolism and invasion of prostate cancer cells. Prostate 73: 1561-1575, 2013.

57. Khan AP, Rajendiran TM, Ateeq B, et al: The role of sarcosine metabolism in prostate cancer progression. Neoplasia 15: 491-501, 2013.

58. Isaacs WB: Inherited susceptibility for aggressive prostate cancer. Asian J Androl 14: 415-418, 2012.

59. Powell IJ, Bock CH, Ruterbusch JJ and Sakr W: Evidence supports a faster growth rate and/or earlier transformation to clinically significant prostate cancer in black than in white American men, and influences racial progression and mortality disparity. J Urol 183: 1792-1796, 2010. 